\title{
ARTICLE OPEN \\ Self-management behaviour and support among primary care COPD patients: cross-sectional analysis of data from the Birmingham Chronic Obstructive Pulmonary Disease Cohort
}

\author{
Ainee Khan ${ }^{1}$, Andrew P. Dickens iD $^{2}$, Peymane Adab $^{2}$ and Rachel E. Jordan ${ }^{2}$
}

Self-management support for chronic obstructive pulmonary disease (COPD) patients is recommended by UK national guidelines, but extent of implementation is unknown. We aimed to describe self-management behaviour and support among COPD patients and explore behaviour associated with having a self-management plan. We undertook cross-sectional analysis of self-reported data from diagnosed COPD patients in the Birmingham COPD Cohort study. Questionnaire items relevant to self-management behaviour, knowledge of COPD, receipt of self-management plans and advice from healthcare professionals were examined. Multiple regression models were used to identify behaviour associated with having a self-management plan. One-thousand seventy-eight participants (676 males, 62.7\%, mean age 69.8 (standard deviation 9.0) years) were included. The majority reported taking medications as instructed (940,94.0\%) and receiving annual influenza vaccinations (962, 89.2\%). Only 400 (40.4\%) participants had self-management plans, 538 (49.9\%) reported never having received advice on diet/exercise and 110 (42.7\%) current smokers had been offered practical help to stop smoking in the previous year. General knowledge about COPD was moderate (mean total Bristol COPD Knowledge Questionnaire score: 31.5 (standard deviation 10.7); max score 65), corresponding to $48.5 \%$ of questions answered correctly. Having a self-management plan was positively associated with self-reported adherence to medication (odds ratio $3.10,95 \%$ confidence interval 1.43 to 6.72 ), attendance at a training course (odds ratio $2.72,95 \%$ confidence interval 1.81 to 4.12 ), attendance at a support group (odds ratio $6.28,95 \%$ confidence interval 2.96 to 13.35 ) and better disease knowledge (mean difference 4.87, 95\% confidence interval 3.16 to 6.58). Primary care healthcare professionals should ensure more widespread implementation of individualised self-management plans for all patients and improve the lifestyle advice provided.

npj Primary Care Respiratory Medicine (2017)27:46; doi:10.1038/s41533-017-0046-6

\section{INTRODUCTION}

Chronic obstructive pulmonary disease (COPD) is an important long-term condition characterised by persistent decline in airflow ${ }^{1}$ and increasing breathlessness. It affects at least $1.9 \%$ of the UK population $^{2}$ and is a costly disease with acute exacerbations being the second leading cause of emergency respiratory hospital admissions in England, ${ }^{3}$ with a similar burden worldwide. Such exacerbations lead to poor prognosis for patients, with reductions in health-related quality of life and increased risk of mortality. ${ }^{4}$

Support to help COPD patients self-manage their condition is recommended by national guidelines to improve their healthrelated quality of life and reduce avoidable inpatient admissions. ${ }^{5,6}$ Exact definitions of self-management and the most effective components of interventions to support patients are ongoing debates. ${ }^{7}$ Self-management support programmes should be collaborative between healthcare professionals and patients, to help them acquire skills to understand and manage their medications and exacerbations, adopt healthier behaviours and manage the social-emotional consequences of the disease..$^{7-11}$ Systematic reviews among patients with COPD show that overall, interventions by healthcare professionals to support patient selfmanagement reduce respiratory-related hospital admissions and improve quality of life, ${ }^{9}$ although the content of the interventions are complex and heterogeneous and which components are the most important is still unclear. ${ }^{12,13}$

Despite limitations in our understanding of which selfmanagement support strategies are the most effective, guidance from the National Institute for Health and Care Excellence (NICE) recommends that all patients with COPD should receive an individualised comprehensive management plan that includes information and educational material about the condition and its management, and that those at risk of exacerbations should be offered advice about how to recognise and respond promptly to the symptoms of an exacerbation. 5,6

The literature describing self-management behaviours of COPD patients in the UK and the support they receive is minimal. ${ }^{14}$ In this paper, we describe the current self-management behaviours of patients with COPD in a large primary care cohort in Birmingham, UK. We also describe the support that patients report receiving from their healthcare professionals and whether a collaborative self-management plan is associated with positive self-management behaviours in real life. Our study, therefore, may help in designing and implementing future self-management interventions.

\footnotetext{
${ }^{1}$ Public Health, Solihull Metropolitan Borough Council, Solihull B91 3QB, UK and ${ }^{2}$ Institute of Applied Health Research, University of Birmingham, Birmingham B15 2TT, UK Correspondence: Andrew P. Dickens (a.p.dickens@bham.ac.uk)
}

Received: 11 February 2017 Revised: 9 June 2017 Accepted: 13 June 2017

Published online: 20 July 2017 


\section{RESULTS}

Study participants

At the time of analysis, $1078 / 1547$ participants (69.7\%) had returned a valid 6-month questionnaire (Fig. 1).

Of the 1078 respondents, $676(62.7 \%)$ were male, 258 (24.3\%) were current smokers and 653 (61.5\%) were former smokers (Table 1). The mean age was 69.8 (standard deviation (SD) 9.0) years and they were predominately of White ethnicity (997; $97.6 \%)$. The majority were either overweight or obese $(786 ; 72.9 \%)$ and had no formal educational qualifications (597; 60.4\%). A small proportion of the respondents were employed (154; 14.4\%), and over a quarter $(302 ; 29.1 \%)$ were living alone.
Despite being on the COPD register, 128 respondents $(12.7 \%)$ did not meet the NICE criteria for airflow obstruction at the baseline study assessment. Of those that did, most respondents $(701 ; 67.4 \%)$ had mild to moderate disease (GOLD stage 1 and 2 ). Almost two thirds (62.9\%) of respondents reported severe dyspnoea (Medical Research Council (MRC) grade 3-5) and the mean COPD Assessment Test (CAT) score was 19.3 (SD 8.6), indicating moderate impact on patients' lives. The most prevalent co-morbidities reported by patients were hypertension (481; $45.4 \%)$ and asthma (408; 38.5\%). There were no marked differences in baseline characteristics between all included participants diagnosed with COPD and respondents to the 6month questionnaire (Table 1).

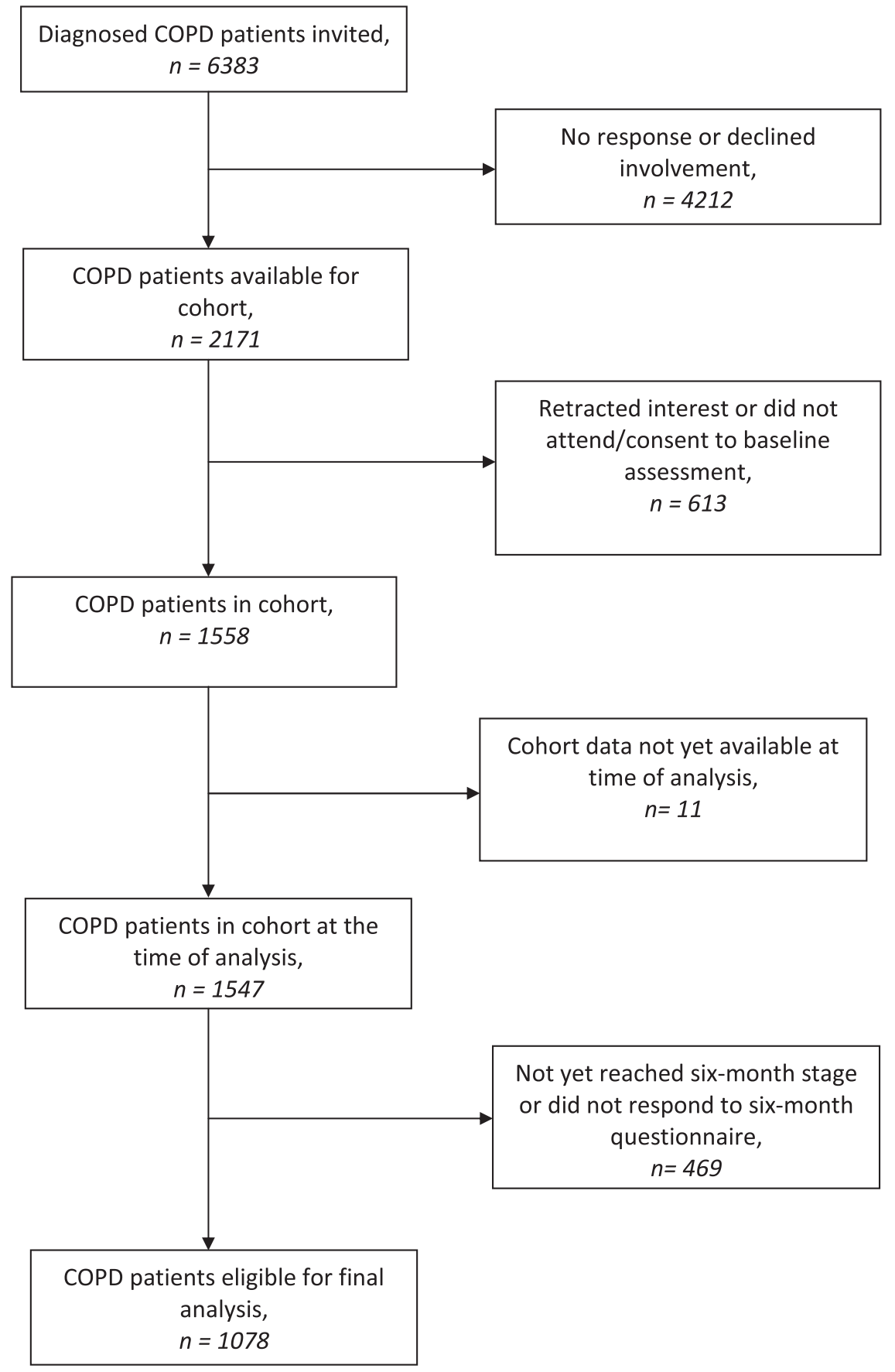

Fig. 1 Flow of participants from cohort to sample 
Table 1. Baseline characteristics: all those eligible for analysis in cohort and respondents to 6-month questionnaire

\begin{tabular}{|c|c|c|}
\hline Characteristic & $\begin{array}{l}\text { All those } \\
\text { diagnosed } \\
\text { with COPD } \\
(n=1547) \\
N(\%)\end{array}$ & $\begin{array}{l}\text { Diagnosed } \\
\text { with COPD } \\
\text { and responded } \\
\text { to 6-month } \\
\text { questionnaire } \\
(n=1078) \\
N(\%)\end{array}$ \\
\hline \multicolumn{3}{|l|}{ Age (years) } \\
\hline Mean (SD) & $69.2(9.4)$ & $69.8(9.0)$ \\
\hline \multicolumn{3}{|l|}{ Sex } \\
\hline Male & $952(61.5 \%)$ & $676(62.7 \%)$ \\
\hline Female & 595 (38.5\%) & $402(37.3 \%)$ \\
\hline \multicolumn{3}{|l|}{ Smoking status } \\
\hline Current-smoker & $402(26.6 \%)$ & $258(24.3 \%)$ \\
\hline Former-smoker & $867(57.4 \%)$ & $653(61.5 \%)$ \\
\hline Never-smoker & $242(16.0 \%)$ & $151(14.2 \%)$ \\
\hline \multicolumn{3}{|l|}{ Body mass index } \\
\hline Underweight $<18.5$ & $33(2.1 \%)$ & $23(2.1 \%)$ \\
\hline Normal 18.5-25 & 387 (25.0\%) & 269 (25.0\%) \\
\hline Overweight $25-30$ & $566(36.6 \%)$ & $403(37.4 \%)$ \\
\hline Obese $>30$ & $561(36.3 \%)$ & $383(35.5 \%)$ \\
\hline \multicolumn{3}{|l|}{ Ethnicity } \\
\hline White & 1377 (97.0\%) & 997 (97.6\%) \\
\hline Any other & $43(3.0 \%)$ & $25(2.4 \%)$ \\
\hline \multicolumn{3}{|l|}{ Education } \\
\hline No formal qualification & $838(61.2 \%)$ & $597(60.4 \%)$ \\
\hline GCSE/A-level & $288(21.0 \%)$ & 202 (20.4\%) \\
\hline Degree & $93(6.8 \%)$ & $74(7.5 \%)$ \\
\hline Other qualification & $150(11.0 \%)$ & $115(11.6 \%)$ \\
\hline \multicolumn{3}{|l|}{ Employment status } \\
\hline Paid/self-employed & $245(16.0 \%)$ & 154 (14.4\%) \\
\hline Not working & $1286(84.0 \%)$ & $919(85.6 \%)$ \\
\hline \multicolumn{3}{|l|}{ Marital status } \\
\hline Married/civil partner & $805(60.2 \%)$ & $605(62.1 \%)$ \\
\hline Never married/civil partner & $101(7.6 \%)$ & $72(7.4 \%)$ \\
\hline Widowed & $230(17.2 \%)$ & $166(17.0 \%)$ \\
\hline Divorced & $177(13.2 \%)$ & $116(11.9 \%)$ \\
\hline Separated & $24(1.8 \%)$ & $16(1.6 \%)$ \\
\hline \multicolumn{3}{|l|}{ GOLD stage $\mathrm{e}^{\mathrm{a}}$} \\
\hline FEV1/FVC $\geq 0.7$ & $200(13.7 \%)$ & $128(12.3 \%)$ \\
\hline $1\left(\mathrm{FEV}_{1} \geq 80 \%\right.$ predicted $)$ & $308(21.1 \%)$ & $225(21.6 \%)$ \\
\hline $2\left(50 \% \leq \mathrm{FEV}_{1}<80 \%\right.$ predicted $)$ & $652(44.7 \%)$ & $476(45.8 \%)$ \\
\hline $3\left(30 \% \leq \mathrm{FEV}_{1}<50 \%\right.$ predicted $)$ & $253(17.4 \%)$ & $179(17.2 \%)$ \\
\hline $4\left(\mathrm{FEV}_{1}<30 \%\right.$ predicted $)$ & $45(3.1 \%)$ & $32(3.1 \%)$ \\
\hline \multicolumn{3}{|l|}{ Self-reported } \\
\hline \multicolumn{3}{|l|}{ Co-morbidities at baseline } \\
\hline Cancer & $183(12.3 \%)$ & $134(12.7 \%)$ \\
\hline Diabetes & $227(15.2 \%)$ & $151(14.3 \%)$ \\
\hline Hypertension & $669(44.8 \%)$ & $481(45.4 \%)$ \\
\hline Coronary heart disease & $226(15.1 \%)$ & $159(15.0 \%)$ \\
\hline Heart failure & $110(7.4 \%)$ & $75(7.1 \%)$ \\
\hline Asthma & 611 (40.9\%) & 408 (38.5\%) \\
\hline
\end{tabular}

\begin{tabular}{|c|c|c|}
\hline \multirow[t]{2}{*}{ Characteristic } & $\begin{array}{l}\text { All those } \\
\text { diagnosed } \\
\text { with COPD } \\
(n=1547)\end{array}$ & $\begin{array}{l}\text { Diagnosed } \\
\text { with COPD } \\
\text { and responded } \\
\text { to 6-month } \\
\text { questionnaire } \\
(n=1078)\end{array}$ \\
\hline & $N(\%)$ & $N(\%)$ \\
\hline Depression & 278 (18.6\%) & 174 (16.4\%) \\
\hline \multicolumn{3}{|l|}{ MRC dyspnoea } \\
\hline Grade $1-2$ & $549(38.1)$ & $391(37.1)$ \\
\hline Grade $3-5$ & $893(61.9)$ & $662(62.9)$ \\
\hline \multicolumn{3}{|l|}{ CAT } \\
\hline Score; mean (SD) & $20.0(8.8)$ & $19.3(8.6)$ \\
\hline \multicolumn{3}{|l|}{ Living situation } \\
\hline Alone & $418(29.0 \%)$ & $302(29.1 \%)$ \\
\hline Not alone & $1021(71.0 \%)$ & 736 (70.9 \%) \\
\hline \multicolumn{3}{|c|}{$\begin{array}{l}\text { NB: Where numbers do not add up to full cohort, values are missing. } \\
\text { Percentages refer to the data available } \\
\text { a GOLD classification severity based on airflow limitation post- } \\
\text { bronchodilator (FEV1 forced expiratory volume during the first second) } \\
\text { based on the European Community of Coal and Steel (ECCS) equations, SD } \\
\text { standard deviation, CAT COPD Assessment Test, GOLD Global Initiative for } \\
\text { Chronic Obstructive Lung Disease, GCSE General Certificate of Secondary } \\
\text { Education }\end{array}$} \\
\hline
\end{tabular}

Identifying self-management behaviours

The majority of respondents $(940 ; 94.0 \%)$ reported taking their inhalers or medications as instructed (Table 2). In the preceding 6 months, most reported no change in smoking habit from baseline (743; 85.5\%), although 105 smokers (12.1\%) reported quitting and 21 (2.4\%) reported taking up smoking. Overall, $89.2 \%$ (962) of patients reported receiving their annual vaccinations, which was comparable between those under or over 65 years old. Most participants reported some form of physical exercise in the last seven days: walking (36.0\%), moderate exercise (19.8\%) and, vigorous exercise $(14.2 \%)$, although participants reported sitting for an average of $5 \mathrm{~h}$ per day.

\section{General COPD knowledge}

The mean overall disease knowledge score of respondents on the Bristol COPD Knowledge Questionnaire (BCKQ) scale was 31.5 (SD 10.7) out of a maximum score of 65 (score range: $0-56$ ). This corresponds to answering $48.4 \%$ of questions correctly (Table 3 ). Patients scored most highly on the five questions about the benefits of smoking cessation (mean 3.3 (SD 1.0) out of 5). Other topics where mean scores were above three included knowledge of recommendations on annual influenza vaccinations and causes of COPD such as smoking and occupational risks. Patients scored lowest on the questions regarding use, benefits and side effects of inhaled steroids (mean 0.7 (SD 1.0) out of 5). There were also low scores on the questions about oral steroids (mean 1.5 (SD 1.4) out of 5).

\section{Exacerbation-related knowledge}

Table 4 describes patients' knowledge of how to recognise and manage exacerbations. Patients who had experienced an exacerbation within the last 6 months tended to be more likely to give the correct answer. In comparison to patients who had not reported an exacerbation in the last 6 months, those reporting an exacerbation were more likely to have both antibiotics ( $45.1 \%$ vs. $17.8 \%, p<0.05)$ and steroids $(40.1 \%$ vs. $14.1 \%, p<0.05)$ at home. Irrespective of prior exacerbation, most patients were confident/ very confident in using both antibiotics and steroids, and reported 
Table 2. Self-management behaviours: adherence to medication and lifestyles

Characteristic

Adherence to medication

Taking inhalers or medicines exactly as instructed by health professional; $n$ (\%)

Yes

$940(94.0 \%)$

No

$60(6.0 \%)$

Smoking habit at 6-months; $n$ (\%)

No change since baseline

Current smoking

Former smoker

Never smoker

Change since baseline

Quit smoking

Started/resumed smoking

$743(85.5 \%)$

$193(22.2 \%)$

$450(51.8 \%)$

$100(11.5 \%)$

$126(14.5 \%)$

$105(12.1 \%)$

$21(2.4 \%)$

Influenza vaccination usually received

Total; $n$ (\%)

Those under 65 years old; $n$

$962(89.2 \%)$

Receiving annual vaccination; $n$ (\%)

297

Those over 65 years old; $n$

Receiving annual vaccination; $n$ (\%)

$258(86.9 \%)$

781

$704(90.1 \%)$

Self-reported exercise in the last 7 days

Vigorous ${ }^{\text {a }}$ exercise; $n$ (\%)

$153(14.2 \%)$

Moderate ${ }^{\mathrm{b}}$ exercise; $n(\%)$

$213(19.8 \%)$

Walking; $n$ (\%)

$388(36.0 \%)$

Hours reported sitting; hours/day; median (IQR)

5 [4-8]

NB: Where numbers do not add up to full cohort, values are missing Percentages refer to the data available

${ }^{a}$ Heavy lifting, digging, aerobics or fast bicycling

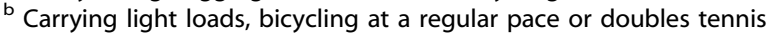

knowing what to do (e.g., adjust bronchodilator therapy or when to call an ambulance) if their breathing deteriorated.

Reporting self-management support

Four-hundred (40.4\%) patients reported having an agreed selfmanagement plan, including only 214 (44.9\%) of those with exacerbations in the last 6 months (Table 5).

The majority of respondents $(773 ; 80.4 \%)$ appeared satisfied with the information given to them by their healthcare professionals about their medications. Of the 258 respondents who were current smokers at baseline, $56.2 \%$ had been advised by a healthcare professional to give up smoking within the last 12 months, and $42.7 \%$ were offered practical help (e.g., nicotine replacement therapy; NRT) to do so. Approximately half of respondents reported ever having been advised about diet or exercise, but only $15.0 \%$ had been advised to lose or gain weight.

Reported attendance at training courses (7.7\%) and support groups (3.1\%) in the last 12 months was low. Of the 72 patients $(6.7 \%)$ that had been offered pulmonary rehabilitation in the past 6 months, 45 (62.5\%) had attended.

Table 6 shows the association between (1) having a selfmanagement plan; (2) exacerbation in the last 6 months; and positive health behaviours, knowledge about COPD and quality of life.
Identifying behaviours associated with having self-management plans

After adjusting for age, sex, smoking status, educational level, MRC dyspnoea score and number of co-morbidities, those who had a self-management plan in place were more likely to have attended a training course (odds ratio (OR) 2.72; 95\% confidence interval $(\mathrm{Cl})$ 1.81-4.12), support group (OR 6.28; 95\% Cl 2.96-13.35), or to have received advice on physical activity (OR 2.44; $95 \% \mathrm{Cl} 1.78-3.35$ ). They were also more likely to have better COPD knowledge scores (mean difference $4.87 ; 95 \% \mathrm{Cl} 3.16-6.58$ ), and self-reported adherence to medication (OR 3.10;95\% Cl 1.43-6.72). These patients also tended to have better CAT scores and were more likely to have been offered NRT, although these effects were not statistically significant.

Effect of exacerbations on self-management behaviour

Patients who experienced an exacerbation within the last 6 months were more likely to have ever attended a training course (OR 1.73; $95 \% \mathrm{Cl} 1.13-2.65$ ) or a support group (OR 2.47; $95 \% \mathrm{Cl} 1.13-5.38$ ), and have better COPD knowledge (mean difference $4.39 ; 95 \% \mathrm{Cl} 2.62-6.15)$ compared to those not reporting an exacerbation (Table 6). In addition, patients with a recent exacerbation were more likely to adhere to medication (OR 2.73; 95\% Cl 1.31-5.69).

\section{DISCUSSION}

Main findings

In this study, we report self-management support and behaviour patterns among a large, broadly representative primary care cohort of COPD patients in England. Although the majority of participants reported taking their medications as instructed by their healthcare professional and receiving annual influenza injections, a striking finding is that less than half of respondents reported having an agreed self-management plan; including patients reporting a recent exacerbation. Similarly, despite $62.9 \%$ reporting severe dyspnoea and, therefore, having the potential to benefit from pulmonary rehabilitation, ${ }^{15}<7 \%$ were referred to the service. This may also explain the lack of self-management advice reported as it is a key component of pulmonary rehabilitation. Of note is that the majority of participants had no formal educational qualifications and over a quarter lived alone, which could have affected whether health professionals discussed or offered selfmanagement plans. ${ }^{16}$ Furthermore, contrary to recommended guidance, ${ }^{5}$ less than half of patients with a recent exacerbation reported having antibiotics or steroids to take at home (rescue pack) if necessary.

Our findings indicate clear potential for improvement in the promotion of healthy lifestyles, considering that only $56 \%$ of current smokers reported receiving smoking cessation advice in the last year. In addition, only $15 \%$ were advised about weight management despite nearly three quarters of the sample being either overweight or obese and $2 \%$ being underweight.

It was interesting to note that participants' general knowledge about COPD (BCKQ) was moderate, and improvement here has potential. Despite patients' poor knowledge regarding the use and benefit of inhaled medications, the high proportion of patients reporting satisfaction with the level of information provided about their medication suggested a discrepancy between perceived and actual knowledge. Attempts to improve the content or mode of delivery of medication information may, therefore, be warranted to optimise patient knowledge of this important area.

Our study indicates various patient benefits associated (though not necessarily causal) with receiving a self-management plan, including increased medication adherence, greater disease knowledge, increased attendance of training courses and support groups, and improved quality of life. However, despite such 
Table 3. Self-management behaviours: Bristol COPD Knowledge Questionnaire (BCKQ)

Topics of $\mathrm{BCKQ}^{\mathrm{a}}$

Mean score (SD)

$(\min =0, \max =5)$

1 General

$2.1(1.1)$

Questions relating to chronicity, progression of disease over time, diagnosis, age of diagnosis and oxygen levels

2 Aetiology

Questions relating to causes: smoking, dust, asthma, inheritance

3 Symptoms

Questions relating to recognising common symptoms: e.g., fatigue, wheezing

4 Breathlessness

Questions relating to breathlessness and to eating meals, oxygen levels and exercise

5 Phlegm

Questions relating to sputum and dehydration, bronchodilators and breathing exercises

6 Infections

Questions relating to signs of infections: sputum colour change, temperature, steroid use in exacerbation

7 Exercise

Questions relating to benefits of exercise and fitness, bone density, depression and breathlessness

8 Smoking

Questions relating to smoking cessation and risk of heart disease, further lung damage, lung function and NRT

9 Vaccination

Questions relating to recommendations of annual influenza vaccination, age and protective factors

10 Inhaled bronchodilators

Questions relating to use of bronchodilators, spacer devices and side effects.

11 Antibiotics

Questions relating to use, side effects, effectiveness of antibiotics and exacerbations

12 Oral steroids

Questions relating to steroid use, infection and side effects

13 Inhaled steroids

Questions relating to use with oral steroids, spacer devices, effectiveness and side effects

Overall BCKQ score (mean (SD))

(110.7)

Distribution of BCKQ $(n(\%))$

$0-13$

$14-26$

37 (5.8\%)

$150(23.7 \%)$

27-39

$295(46.5 \%)$

$40-52$

$144(22.7 \%)$

53-65

$8(1.3 \%)$

NRT nicotine replacement therapy

${ }^{a}$ Each of the 13 topics contained five questions (1 point for a correct answer). Total BCKQ score is out of 65 (13 topics $\times 5$ questions)

benefits, presence of a self-management plan was not associated with practical support, such as NRT, being offered.

Interpretation of findings in relation to previously published work Self-management in COPD is a relatively under-researched topic in comparison with other chronic diseases. ${ }^{17}$ There is little other evidence regarding the reality of patients' self-management behaviour or the support offered by healthcare professionals in the UK.

Our findings that patients adhere well and report understanding their medication reflect those of previous Canadian studies. ${ }^{18-20}$ However, in contrast to our study, a cross-sectional study $^{20}$ found that community-dwelling COPD patients in Canada reported better engagement with other self-management behaviours, where higher proportions of patients engaged in aerobic activity (74\% vs. our $14 \%$ ) and breathing exercises (70\%). They also reported that $68 \%$ of patients made collaborative management decisions with their healthcare professional and $20 \%$ had attended pulmonary rehabilitation.
Although the limited use of self-management plans has previously been reported in two small studies of patients with recent exacerbations in the $\mathrm{UK}^{14}$ and Canada, ${ }^{19}$ our study supports and extends these observations in a larger generalisable primary care population. Furthermore our study adds to this by indicating that, in the UK, self-management plans are also associated with better reported adherence to medication, more support/self-management advice and better quality of life.

Strengths and limitations of this study

We have described major facets within self-management behaviours in a large COPD population, from general practices representative of primary care in the UK.

It is, however, possible that the relatively low recruitment rate into the cohort (24\%) might affect generalisability to a certain extent as participants were more likely to be male and of white British ethnicity than all eligible COPD patients in our participating general practices. $^{21}$ 
Table 4. Self-management behaviours: exacerbation-related symptom recognition and treatments at home

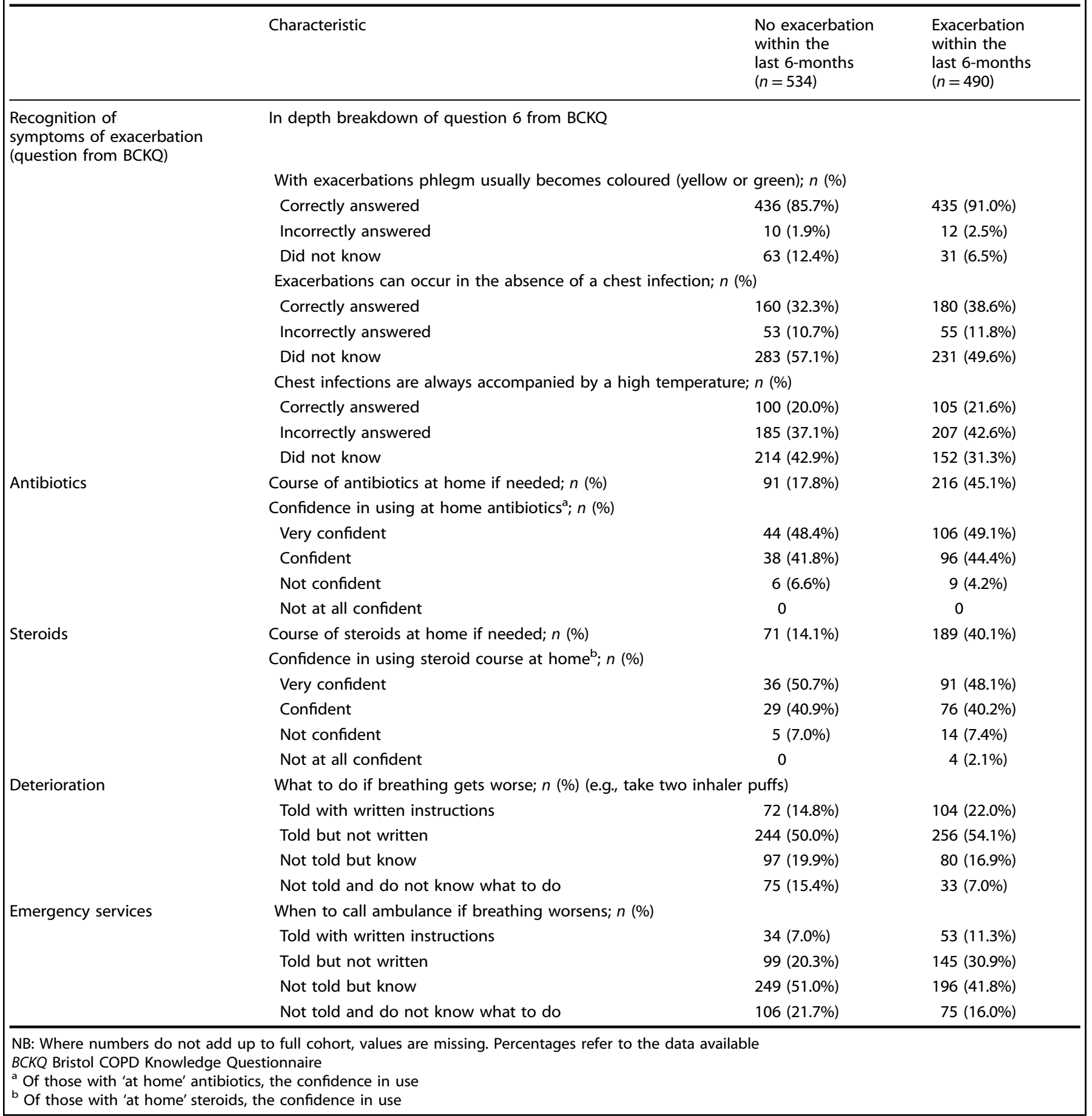

While we have demonstrated that presence of a selfmanagement plan is associated with better support and behaviours, the analyses were conducted using cross-sectional data. Analyses would need to be repeated with longitudinal data to ascertain whether the association was causal, or simply indicated that patients received a better overall package of care from their practitioner.

Study questionnaires completed by patients in the current analysis did not explore patients' self-efficacy and motivation ${ }^{17,22}$ in relation to self-management behaviour. Mediating factors, such as willingness to quit in the case of smoking cessation, would need to be accounted for in analyses to assess the true impact of self-management plans. Inconsistencies in the definition and measurement of self-management ${ }^{7}$ further limit our ability to compare the findings with existing evidence. The date of COPD diagnosis was not available for this analysis; hence we were unable to explore if duration of disease impacted on selfmanagement behaviour or support.

Data presented in this paper were collected via patient selfcompleted questionnaire as objective measures were not feasible, 
Table 5. Self-management support: Plans and healthcare professional advice

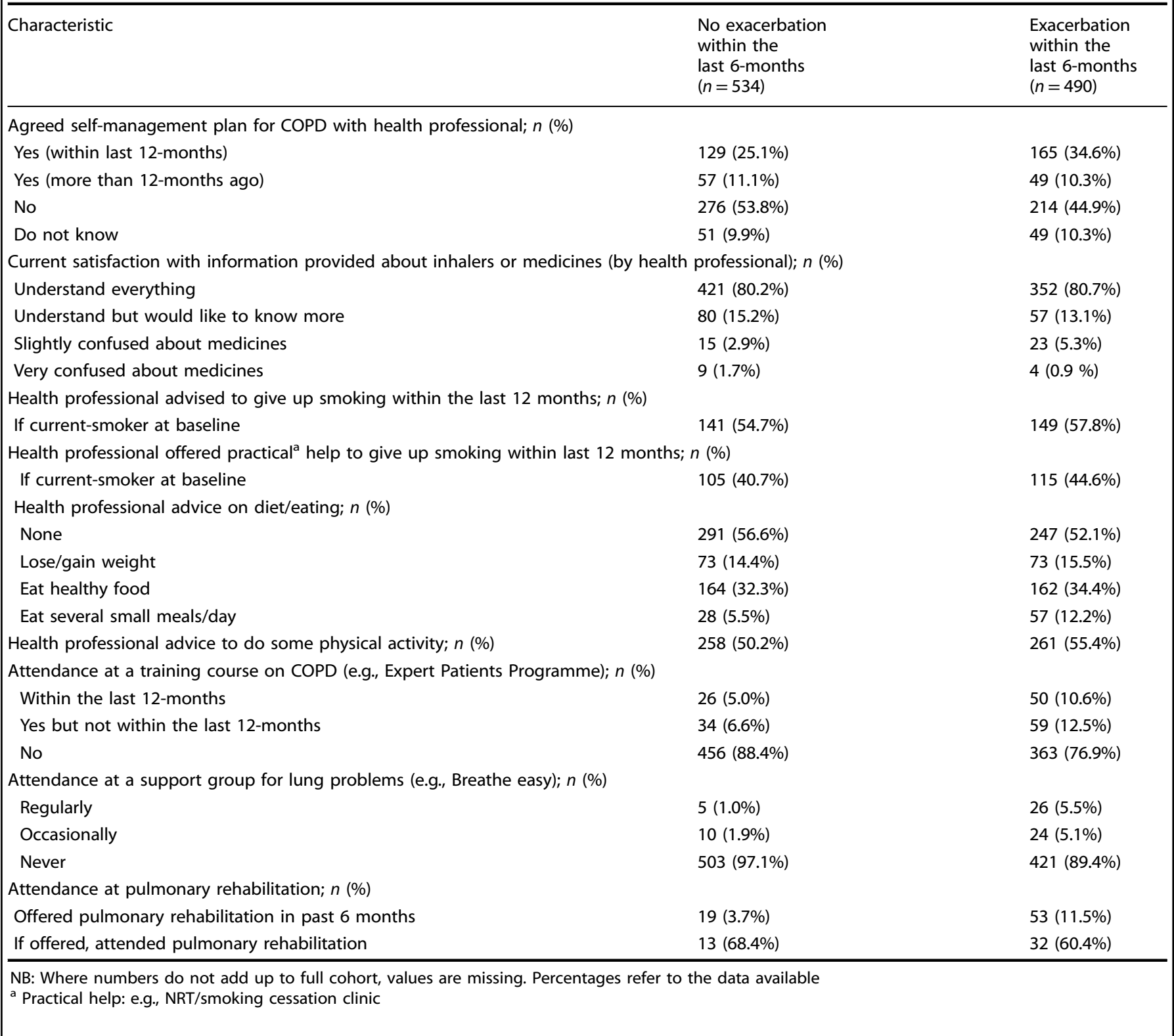

although validated instruments were used where possible. As a result, data should, therefore, be interpreted with appropriate caution, allowing for potential biases. Self-report of behaviours such as compliance with medication is likely to be prone to overestimation by respondents compared with objective measurement. $^{23}$ However, it is unclear whether the relationship between having a self-management plan and adherence to medication would be affected. Additionally, the BCKQ COPD knowledge questionnaire is now dated, and question 13 regarding knowledge about inhaled steroids is no longer current. However, this only represents 5 out of a total of 65 points and the questions about inhaled bronchodilators also scored low marks. We also asked questions regarding the confidence of patients to act (such as to start taking their rescue medication) during their exacerbation. Confidence rates were high, but it is acknowledged that such positive self-efficacy does not always translate into timely action. ${ }^{24}$ We were not able to observe actual self-administration of medication during exacerbations.
Implications for future research, policy and practice

Despite NICE recommendations that all COPD patients should receive an individualised self-management plan, ${ }^{5,6}$ implementation in practice appears clearly inadequate. Understanding this mismatch, particularly from the healthcare practitioner perspective, is an important area for future research in order to understand the potential barriers and enablers involved. Annual reviews of COPD patients in primary care seem the ideal opportunity to discuss self-management, as they are attended by over $90 \%$ of patients ${ }^{2}$ and already include some relevant aspects, e.g., desire to stop smoking, inhaler technique and referral to further services such as pulmonary rehabilitation. Wider health promotion behaviours such as weight management and physical activity were apparently not discussed by healthcare professionals, and had low uptake among patients. Improving the general health of patients could benefit management of their COPD symptoms, such as breathlessness, and improve outcomes. $^{25}$ 
Table 6. Knowledge, behaviours and advice associated with having a self-management plan and report of recent exacerbation

\begin{tabular}{|c|c|c|}
\hline \multicolumn{3}{|l|}{ Attendance at training course ${ }^{b}$} \\
\hline \multicolumn{3}{|l|}{ Attendance at support group ${ }^{d}$} \\
\hline $\mathrm{OR}^{\mathrm{c}}(95 \% \mathrm{Cl})$ & $6.28(2.96,13.35)^{*}$ & $2.47\left(1.13,5.38^{*}\right)^{*}$ \\
\hline \multicolumn{3}{|c|}{ Offered NRT by healthcare professional ${ }^{\mathrm{e}}$} \\
\hline $\mathrm{OR}^{\mathrm{C}}(95 \% \mathrm{Cl})$ & $1.40(0.83,2.38)$ & $0.90(0.53,1.55)$ \\
\hline \multicolumn{3}{|l|}{ Adherence to medications $^{f}$} \\
\hline $\mathrm{OR}^{\mathrm{c}}(95 \% \mathrm{Cl})$ & $3.10(1.43,6.72)^{*}$ & $2.73(1.31,5.69)^{*}$ \\
\hline \multicolumn{3}{|c|}{ Ever advised to carry out physical activity by health professional } \\
\hline \multicolumn{3}{|c|}{$\begin{array}{l}{ }^{*} p \text {-value }<0.05 \\
\text { a Self-management/personal care plan ever agreed with a health professional, i.e., }<12 \text { months or }>12 \text { months ago } \\
\text { b Ever attended a training (e.g., Expert Patients Programme) course i.e., }<12 \text { months or }>12 \text { months ago } \\
\text { c Adjusted for age, gender, smoking status, education, MRC dyspnoea score and co-morbidities } \\
\text { d Ever attended a support (e.g., Breathe Easy) group i.e., regularly or occasionally } \\
\text { e Health professional offering help to give up smoking (e.g., NRT or a referral to a smoking cessation clinic) within last } 12 \text { months regardless of smoking status } \\
\text { f Adherence: trying to take inhalers or medicines exactly as instructed by a doctor or nurse }\end{array}$} \\
\hline
\end{tabular}

The time constraint within primary care consultations is a potential barrier to the inclusion of thorough self-management support, ${ }^{25}$ with an alternative being referrals to allied services. However, the majority of patients (especially those without selfmanagement plans) had never attended a training course, a support group or pulmonary rehabilitation, indicating a lack of self-management support outside primary care-based patient and healthcare professional interactions. Further research is needed to explore the adequacy of referral pathways in primary care, whether resources are available to support training courses and pulmonary rehabilitation, as well as patients' reasons for poor participation in existing services. ${ }^{26}$

Future implementation research ${ }^{27}$ is needed to explore how to expand current self-management recommendations to all COPD patients, within the confines of current financial constraints.

Finally, engaging the patient in their condition is a major challenge for health professionals managing COPD and other long-term health conditions, which if achieved could improve patients' self-management behaviour. Studies report compliance rates of approximately $40 \%$ with self-management advice among patients with COPD, 28,29 with those who successfully self-manage their condition being younger and not living alone. Recent evidence suggests that motivation of non-compliant patients may be enhanced through multimodal approaches (e.g., health coaching, counselling, pulmonary rehabilitation), reporting reductions in readmissions and improved quality of life. ${ }^{30}$

\section{CONCLUSIONS}

This study increases understanding about the real life practice of self-management behaviours in COPD patients. Patients are indeed partially using a self-management approach in their condition as recommended by bodies such as NICE. Adults with COPD are using inhaled medications, having annual influenza vaccinations, and some are engaging in partnerships with the healthcare service. However, healthcare professionals need to make explicit self-management plans with all of their patients, provide consistent advice and offer practical support regarding smoking cessation, diet, exercise and attendance at support groups, and actively ensure that their patients understand their condition and its management. This may require a new approach in primary care to achieve satisfactory implementation.

\section{METHODS}

Study design

Cross-sectional analysis of data collected as part of the Birmingham COPD Cohort Study between 2011 and 2015, to establish self-management behaviours and support; and outcomes associated with having a selfmanagement plan among primary care patients with COPD.

\section{Setting and participants}

Recruitment to the Birmingham COPD Cohort Study has been described elsewhere. ${ }^{21}$ The cohort comprises patients with existing diagnosed COPD, newly case-found COPD and those with chronic respiratory symptoms without airflow obstruction. This analysis focuses on those with existing diagnosed COPD. Briefly, 6383 patients aged 40 years or over with a GPrecorded COPD diagnosis from 71 general practices across the West Midlands, UK, were invited to take part, of whom 1558 (24.4\%) were eventually consented into the study. At the time of this analysis, 1547 had consented. The current analysis was based on prevalent patients with 6-month questionnaire data $(n=1078)$, which specifically asked about self-management behaviours.

\section{Data collection}

Participants attended a baseline study assessment at their own GP practice, conducted by trained research assistants. Patients completed questionnaires at this assessment and then at 6-monthly intervals, with a further final face-to-face clinical assessment at approximately three years. The questionnaires were self-completed and included items on sociodemographic characteristics, health (including health related quality of life and co-morbidities), lifestyle behaviours, medications, health service usage and disease knowledge. Validated tools were used where possible. Data for the current analyses came primarily from the 6-month questionnaire or baseline assessment as appropriate. 
Data and variables

At baseline assessment, trained research assistants performed spirometry using the nddEasy One spirometer (ndd, Switzerland), pre and post administration of $400 \mu \mathrm{g}$ salbutamol. A minimum of three and a maximum of six blows post-bronchodilator were allowed, until repeatability within $100 \mathrm{mls}$ was reached and the best reading was recorded. Specialised software (MMiller) and real-time show of volume-time and flow-volume graphs were used to ensure quality. All traces were over-read and data for forced expiratory volume in $1 \mathrm{~s}\left(\mathrm{FEV}_{1}\right)$ and forced vital capacity (FVC) were deemed viable if they met American Thoracic Society acceptability criteria and were repeatable to within $200 \mathrm{ml}$. COPD was defined as airflow obstruction using a fixed ratio of $\mathrm{FEV}_{1} / \mathrm{FVC}<0.70$ and severity was graded according to the European Community of Coal and Steel (ECCS) equations. ${ }^{31}$

We included several variables describing self-management knowledge and behaviour in the 6-month questionnaire (Supplementary information 1). The BCKQ has 13 main themes each with five sub questions, and measures patients' general knowledge about COPD (higher scores indicating higher knowledge). ${ }^{32}$ Physical activity levels were measured using the International Physical Activity Questionnaire. ${ }^{33}$ We also asked patients to report whether they took medications as prescribed, if they had a course of antibiotics and steroids at home to take in the event of an exacerbation and confidence in their use, their smoking habit and receipt of influenza vaccinations.

Variables describing self-management support included: having an agreed self-management plan with a health professional, satisfaction with information on how to take medications and inhalers, advice from healthcare professionals on nutrition, physical activity and smoking cessation. We also asked about attendance at training or support courses on COPD and pulmonary rehabilitation.

Disease specific quality of life was assessed using the CAT. ${ }^{34}$ The MRC dyspnoea score was used to assess degree of breathlessness. ${ }^{35} \mathrm{Co}-$ morbidities of interest included cancer, diabetes, hypertension, coronary heart disease, heart failure, asthma and depression. Exacerbations were defined as the report of one or more courses of either steroids or antibiotics taken within the time period.

\section{Statistical analyses}

All analyses were undertaken in Stata $13 .^{36}$ The characteristics of the study population, self-management behaviour and support were described using simple descriptive statistics. Analyses were stratified by the experience of an exacerbation within the last 6 months to determine whether this affected symptom recognition, available treatments at home and selfmanagement support provided by healthcare professionals. Multiple regression models were used to investigate the relationship between (1) having a self-management plan, (2) having an exacerbation within the previous 6 months, and reported self-management behaviours and support, adjusting for age, sex, smoking status, education, MRC dyspnoea score and co-morbidities.

\section{Ethics}

The cohort received ethical approval from the National Research Ethics Service Committee West Midlands, Solihull (ref.: 11/WM/0304). Methods were performed in accordance with relevant regulations and guidelines. Written informed consent was obtained from each participant at the start of the baseline assessment.

\section{Data availability}

The data that support the findings of this study are held by the BLISS research team at the University of Birmingham. Copies of the questionnaires, measurement procedures and administrative processes are available on request, through our website [www.birmingham.ac.uk/bliss]. The data are not publicly available due to them containing information that could compromise research participant privacy/consent.

\section{ACKNOWLEDGEMENTS}

We would like to thank the patients that participated in our study, as well as the support of their general practices. We would also like to thank our patient advisory group and programme steering committee. Finally, we would like to acknowledge the BLISS research team. This paper summarises independent research funded by the National Institute for Health Research (NIHR) under its Programme Grants for Applied
Research Programme (grant reference number RP-PG-0109-10061). The views expressed are those of the authors and not necessarily those of the NHS, the NIHR or the Department of Health. The Birmingham COPD Cohort study is part of the Birmingham Lung Improvement StudieS: BLISS.

\section{AUTHOR CONTRIBUTIONS}

The idea for this study was conceived and developed by R.J. R.J. is the guarantor. R.J./A.D./A.K. designed the protocol for data extraction. A.D. extracted data to create the data file. A.K. undertook analyses of the data with advice and input from R.J./A.D./P.A. A.K. wrote the manuscript with advice and input from R.J./A.D./P.A. All authors take responsibility for the integrity of the data and accuracy of the data analysis. All authors agreed to the final version.

\section{ADDITIONAL INFORMATION}

Supplementary Information accompanies the paper on the npj Primary Care Respiratory Medicine website (doi:10.1038/s41533-017-0046-6).

Competing interests: The authors declare no competing financial interests.

Publisher's note: Springer Nature remains neutral with regard to jurisdictional claims in published maps and institutional affiliations.

\section{REFERENCES}

1. Vestbo, J. et al. Global strategy for the diagnosis, management, and prevention of chronic obstructive pulmonary disease. Am. J. Respir. Crit. Care Med. 187, 347-365 (2013).

2. Jamie G. UK-QOF Database [Internet]. Gpcontract.co.uk. 2015 [cited 16 November 2015]. Available from: http://www.gpcontract.co.uk/.

3. Gov.uk. An Outcomes Strategy for COPD and Asthma: NHS Companion Document- Publications-GOV.UK [Internet]. 2012 [cited 16 November 2015]. Available from: https://www.gov.uk/government/publications/an-outcomesstrategy-for-copd-and-asthma-nhs-companion-document.

4. Gudmundsson, G. et al. Mortality in COPD patients discharged from hospital: the role of treatment and co-morbidity. Respir. Res. 7, 109 (2006).

5. Nice.org.uk. Chronic Obstructive Pulmonary Disease in Over 16s: Diagnosis and Management|1-Recommendations|Guidance and Guidelines|NICE [Internet]. 2010 [cited 12 November 2015]. Available from: http://www.nice.org.uk/ guidance/cg101/chapter/1-recommendations.

6. Nice.org.uk. Chronic Obstructive Pulmonary Disease in Adults|Quality-Statement2-Management-Planning|Guidance and Guidelines|NICE [Internet]. 2011 [cited 17 November 2015]. Available from: https://www.nice.org.uk/guidance/qs10/chapter/quality-statement-2-management-planning.

7. Effing, T. et al. Self-management programmes for COPD moving forward. Chron. Respir. Dis. 9, 27-35 (2012).

8. Bourbeau, J. \& van der Palen, J. Promoting effective self-management programmes to improve COPD. Eur. Respir. J. 33, 461-463 (2009).

9. Zwerink, M. et al. Self management for patients with chronic obstructive pulmonary disease. Cochrane Database Syst. Rev. 3, (2014).

10. Spruit, M. et al. An official American thoracic society/European respiratory society statement: key concepts and advances in pulmonary rehabilitation. Am. J. Respir. Crit. Care. Med. 188, e13-e64 (2013).

11. Sohanpal, R., Epiphaniou, E. \& Taylor, S. Self-management for COPD?: Why does it generate negative connotations? Br. J. Gen. Pract 64, e522-e524 (2014).

12. Jordan, R. et al. Supported self-management for patients with moderate to severe chronic obstructive pulmonary disease (COPD): an evidence synthesis and economic analysis. Health Technol. Assess. 19, 1-516 (2015).

13. Majothi, S. et al. Supported self-management for patients with COPD who have recently been discharged from hospital: a systematic review and meta-analysis. Int. J. Chron. Obstruct. Pulmon. Dis. 10, 853-867 (2015).

14. Stone, R. et al. What happens to COPD patients before an admission with exacerbation?. Prim. Health Care Res. Dev. 13, 395-402 (2012).

15. National Institute for Health and Care Excellence. Chronic Obstructive Pulmonary Disease: Management of Chronic Obstructive Pulmonary Disease in Adults in Primary and Secondary Care. London: National Institute for Health and Care Excellence, 2010.

16. Tøttenborg, S. et al. Socioeconomic inequalities in adherence to inhaled maintenance medications and clinical prognosis of COPD. Respir. Med. 119, 160-167 (2016).

17. Kaptein, A., Fischer, M., Scharloo, M. Self-management in patients with COPD: theoretical context, content, outcomes, and integration into clinical care. Int. J. Chron. Obstruct. Pulmon. Dis. 9, 907-917 (2014). 
18. Cicutto, L. \& Brooks, D. Self-care approaches to managing chronic obstructive pulmonary disease: a provincial survey. Respir. Med. 100, 1540-1546 (2006).

19. Hernandez, P., Balter, M., Bourbeau, J. \& Hodder, R. Living with chronic obstructive pulmonary disease: a survey of patients' knowledge and attitudes. Respir. Med. 103, 1004-1012 (2009).

20. Hernandez, P. et al. Canadian practice assessment in chronic obstructive pulmonary disease: Respiratory specialist physician perception versus patient reality. Can. Respir. J 20, 97-105 (2013).

21. Adab P. et al. Cohort profile: the birmingham COPD cohort study. Int. J. Epidemiol. 1-10 (2016) doi:10.1093/ije/dyv350.

22. Barlow, J., Wright, C., Sheasby, J., Turner, A., Hainsworth, J. Self-management approaches for people with chronic conditions: a review. Pat. Educ. Counsel. 48, 177-187 (2002).

23. Vestbo, J. et al. Adherence to inhaled therapy, mortality and hospital admission In COPD. Thorax 64, 939-943 (2009).

24. Williams, V., Hardinge, M., Ryan, S., Farmer, A. Patients' experience of identifying and managing exacerbations in COPD: a qualitative study. Npj Prim. Care Respir. Med. 24, (2014) doi:10.1038/npjpcrm.2014.62.

25. Kennedy, A. et al. Implementation of a self-management support approach (WISE) across a health system: a process evaluation explaining what did and did not work for organisations, clinicians and patients. Implement Sci. 9, 129 (2014) doi:10.1186/s13012-014-0129-5.

26. Sohanpal, R., Seale, C., Taylor, S. Learning to manage COPD: a qualitative study of reasons for attending and not attending a COPD-specific self-management programme. Chron. Respir. Dis. 9, 163-174 (2012).

27. Peters, D., Adam, T., Alonge, O., Agyepong, I. \& Tran, N. Implementation research: what it is and how to do it. BMJ 347, f6753 (2013).

28. Bischoff, E. et al. Effects of written action plan adherence on COPD exacerbation recovery. Thorax 66, 26-31 (2010).

29. Bucknall, C. et al. Glasgow supported self-management trial (GSuST) for patients with moderate to severe COPD: randomised controlled trial. BMJ 344, e1060-e1060 (2012).
30. Benzo, R. et al. Health coaching and chronic obstructive pulmonary disease rehospitalization. A Randomized Study. Am. J. Respir. Crit. Care 194, 672-680 (2016).

31. Kuster, S. et al. Reference equations for lung function screening of healthy never-smoking adults aged 18-80 years. Eur. Respir. J. 31, 860-868 (2008).

32. White, R., Walker, P., Roberts, S., Kalisky, S. \& White, P. Bristol COPD knowledge questionnaire (BCKQ): testing what we teach patients about COPD. Chron. Respir. Dis. 3, 123-131 (2006).

33. Lee, P., Macfarlane, D., Lam, T., Stewart, S. Validity of the international physical activity questionnaire short form (IPAQ-SF): a systematic review. Int. J. Behav. Nutr. Phys. Act. 8, (2011) doi:10.1186/1479-5868-8-115.

34. Jones, P. et al. Development and first validation of the COPD Assessment Test. Eur. Respir. J. 34, 648-654 (2009).

35. Stenton, C. The MRC breathlessness scale. Occup. Med. 58, 226-227 (2008).

36. StataCorp. Stata Statistical Software: Release 13. (StataCorp LP, 2013).

Open Access This article is licensed under a Creative Commons Attribution 4.0 International License, which permits use, sharing, adaptation, distribution and reproduction in any medium or format, as long as you give appropriate credit to the original author(s) and the source, provide a link to the Creative Commons license, and indicate if changes were made. The images or other third party material in this article are included in the article's Creative Commons license, unless indicated otherwise in a credit line to the material. If material is not included in the article's Creative Commons license and your intended use is not permitted by statutory regulation or exceeds the permitted use, you will need to obtain permission directly from the copyright holder. To view a copy of this license, visit http://creativecommons. org/licenses/by/4.0/.

(c) The Author(s) 2017 